\title{
Screening program in the athlete in the suspicion of HCM
}

\author{
Maddalena Piro $^{1}$, Maria Grazia Roccia ${ }^{2}$, Carolina Jahaira Aracena ${ }^{1}$, Maria Bianchi ${ }^{1}$ and Fioranelli Massimo $^{1 *}$ \\ ${ }^{1}$ G.Marconi University, Rome, Italy \\ ${ }^{2}$ University B.I.S. group of institutions, Punjab Technical University, Punjab, India
}

\section{Introduction}

Hypertrophic Cardiomyopathy (HCM) represents one of the most important causes of sudden death in young athletes. Pre-participation screening in healthy general athlete populations may raise the suspicion of HCM and ultimately lead to definitive diagnosis. However, recently controversy has arisen regarding the most effective and practical strategy for the screening of athletes. European investigators have promoted routine 12-lead ECGs as part of a national mandatory programme distinct from the customary practice in the United States of America (USA) which is limited to history and physical examinations. Consensus criteria and recommendations for eligibility and disqualification of athletes with HCM have proved useful to the practicing community.

\section{Aim of the article}

HCM is a complex and relatively common genetic cardiac disease and represents an important cause of disability and death in patients of all ages, although sudden death in young people is the most devastating component of its natural history. In the USA, HCM represents the first cause of sudden death in young athletes (36\% of total) [1]. Because of marked heterogeneity in clinical expression, natural history and prognosis, HCM often represents a dilemma to primary care clinicians and cardiovascular specialists. Subsequently difficult questions often arise, particularly among practitioners infrequently engaged in the evaluation of HCM.

This review article represents a particularly useful contribution to the literature for health care professionals, especially cardiologists (also fellows) and sport medicine physicians, helping them in making eligibility or disqualification decision, to prevent tragic events, such as sudden death that represents the most crucial event in sport life.

\section{Main part}

Hypertrophic cardiomyopathy is inherited as a mendelian autosomal dominant trait and caused by mutations in any 1 of 10 genes, each encoding proteins of the cardiac sarcomere (components of thick or thin filaments with contractile, structural, or regulatory functions). Three of the HCM-causing mutant genes predominate, namely, $\beta$-myosin heavy chain (the first identified), cardiac troponin $\mathrm{T}$, and myosin-binding protein $\mathrm{C}$. The other genes each account for a minority of HCM cases, namely, cardiac troponin I, regulatory and essential myosin light chains, titin, $\alpha$-tropomyosin, $\alpha$-actin, and $a$-myosin heavy chain [2]. This diversity is compounded by intragenic heterogeneity, with more than 150 mutations identified, most of which are missense with a single aminoacid residue substituted with another. Molecular defects responsible for HCM are usually different in unrelated individuals, and many other genes and mutations, each accounting for a small proportion of familial HCM, remain to be identified (Table 1).

The clinical diagnosis of HCM is based on the echocardiographic definition of the typical features of the disease that are the following: asymmetric hypertrophy of the left ventricle ( $\mathrm{LVH})$, in association with a normal endocavitary dimensions, and absence of another cardiac or systemic disease (eg, hypertension or aortic stenosis) capable of producing the magnitude of hypertrophy.

Given that most patients do not have LV outflow tract obstruction at rest and most of the well-documented physical findings (eg, loud systolic heart murmur and bifid arterial pulse) are limited to patients with outflow gradients, the signs suggestive of a dynamic LVOT obstruction, such as a systolic heart murmur, a Systolic Anterior Motion (SAM) of the mitral valve or a premature closure of the aortic valve, do not represent diagnostic criteria.

LVH represents an independent risk factor for the sudden death in young people affected by HCM and is variable in distribution and extension $[1,2]$.

Although many patients show diffusely distributed LVH, almost one third have mild wall thickening localized to a single segment (interventricular septum, apex, antero-lateral and posterior wall), including the apical form, that appears most commonly in Japanese

Table 1. Genetic of HCM (by Chapter 19, Sport Cardiology Texbook, Springer 2012).

\begin{tabular}{|l|l|l|}
\hline Gene & $\begin{array}{l}\text { Abbr. } \\
\text { Gene }\end{array}$ & Locus $s$ \\
\hline$\beta$-myosin heavy chain & MYH7 & $14 \mathrm{q} 12$ \\
\hline$\alpha$-myosin heavy chain & MYH6 & $14 \mathrm{q} 12$ \\
\hline Regulatory myosin light chain & MYL2 & $12 \mathrm{q} 23-\mathrm{q} 24$ \\
\hline Essential myosin light chain & MYL3 & $3 \mathrm{p} 21$ \\
\hline Myosin binding protein C & MYBPC3 & $11 \mathrm{p} 11.2$ \\
\hline Troponin T & TNNT2 & $1 \mathrm{q} 32$ \\
\hline Troponin I & TNNI3 & $19 \mathrm{q} 13.4$ \\
\hline$\alpha$-tropomyosin & TPM1 & $15 \mathrm{q} 22.1$ \\
\hline Protein-kinase 2 & PRKAG2 & $7 \mathrm{q} 36$ \\
\hline Muscle LIM proteins & CSRP3 & $11 \mathrm{p} 15.1$ \\
\hline Titin (connectin) & TTN & $2 \mathrm{q} 24.3$ \\
\hline Actin & ACTC1 & $15 \mathrm{q} 14$ \\
\hline Troponin C & TNNC1 & $3 \mathrm{p} 21-\mathrm{p} 14$ \\
\hline & & \\
\hline
\end{tabular}

Correspondence to: Fioranelli Massimo, University B.I.S. group of institutions, Punjab Technical University, Punjab, India; E-mail: massimo.fioranelli@gmail.com

Received: January 20, 2015; Accepted: February 12, 2015; Published: February 15,2015 
people. In clinically diagnosed patients, increased LV wall thicknesses range widely from mild $(13-15 \mathrm{~mm})$ to massive $(30 \mathrm{~mm}$ [normal, $12 \mathrm{~mm}]$ ), up to $60 \mathrm{~mm}$.

In trained athletes, modest segmental wall thickening (ie, 13$15 \mathrm{~mm}$ ) raises the differential diagnosis between extreme physiologic LVH (ie, athlete's heart) and mild morphologic expressions of HCM, without outflow obstruction.

The differential diagnosis in this "gray-zone" of overlap (about $2 \%$ of elite male athletes) can usually be resolved with some clinical and echocardiographic criteria. An end-diastolic diameter (EDD) $>55 \mathrm{~mm}$ and a reduction of the LV wall thickening after three months of detraining $(<13 \mathrm{~mm})$ are suggestive of the athlete's heart $[3,4]$. Differentiation of adaptative LVH versus HCM in a gray zone population could be facilitated by recognition of certain features referring to LV dimensions, diastolic function and brain natriuretuc peptide (BNP) [5,6]. In a pilot study by Pagourelias et al., LVEDD $<4,74$, mitral deceleration on time $>200 \mathrm{msec}$, isovolumic relaxation time $>94 \mathrm{msec}$, tricuspid $\mathrm{E} / \mathrm{A}<1,63$, relative wall thickness $>0,445$ and a BNP value at rest $>9,84 \mathrm{pg} / \mathrm{ml}$ had a greater probability for having underlying cardiomyopathy [5].

Magnetic Resonance Imaging (MRI) may be of diagnostic value when echocardio- graphic studies are technically inadequate or in identifying segmental LVH undetectable by echocardiography [7]. A model incorporating the LV End Diastolic Volume (EDV) and End Diastolic Mass (EDM) ratio (EDV:EDM ratio) has been proposed as a useful tool to distinguish HCM from physiological hypertrophy in athletes [8]. This ratio has been found to be lower in patients with HCM in comparison with healthy controls and athletes. Thus, the LV EDV:EDM ratio may be applied to cases with borderline $\mathrm{LVH}$, which present the greatest diagnostic challenge in clinical practice.

Moreover late gadolinium enhancement may be helpful in identifying areas of intramyocardial fibrosis [7]. However, on the other hand, MRI of endurance athletes has been found to reveal abnormal findings in more than $5 \%$ of the athletes [9]. Thus, cardiac MRI cannot be recommended as a routine examination in the care of athlete.

Also the cardiopulmonary test may contribute to the differential diagnosis between HCM and the athlete's heart: the athletes have usually a VO2 peak value $>50 \mathrm{ml} / \mathrm{kg} / \mathrm{min}$, in comparison with $\mathrm{HCM}$ patients that presents $\mathrm{VO} 2$ peak value in the range of normality [7].

Actually genetic analysis is useful in distinguishing the benign consequences of systematic athletic training from pathological LVH with the potential for sudden cardiac death [2]. With regard to pedigree assessment, it is obligatory for the proband to be informed of the familial nature and autosomal dominant transmission of HCM. Screening of first-degree relatives, including anamnestic and physical examinations, and 2-dimensional echocardiography and ECG should be encouraged, particularly if adverse HCM-related events have occurred in the family. If a proband is positive for one of the 10 most common HCM-causing mutant genes tested in the panel, the test result is definitive. On the other hand, negative tests in probands may be nondiagnostic because of the false negative results. However, if the gene defects responsible for HCM in the family becomes known, then other family members can easily be tested definitively and inexpensively [7]. Actually, such genetic testing has potential limitations and the debate regarding screening remains controversial.

Genetic testing has been employed increasingly in diagnosing $\mathrm{HCM}$, resulting in a subset of patients with genotype positive- phenotype negative disease; these patients carry the mutation for HCM but lack pathological evidence of disease [10]. Thus, a growing body of evidence continues to disagree, in regard to the treatment for phenotypically normal HCM.

The importance of a correct risk stratification and the eventual sport disqualification in HCM affected patients are based on the evidence that sudden death often represents the first clinical manifestation of the disease, in particular in young people ( $<30$ years).

The vast majority of athletes who die suddenly with HCM are free of symptoms or suspicion of cardiovascular disease [1]. Sudden collapse usually occurs with physical exertion, predominantly in the late afternoon and early evening hours, corresponding to the peak periods of competition and training, and particularly in organized team sports, such as football and basketball [11]. In addition, underlying genetic heart diseases are more likely to cause sudden unexpected death in trained athletes than in their sedentary counterparts. These observations substantiate that, in the presence of cardiovascular disease, physical activity represents a trigger and important precipitating factor for sudden death in athletes.

The vast majority of athletic field deaths occur in men (about $90 \%$ ). This relative infrequency in women probably reflects lower participation rates, sometimes less intense levels of training, and the fact that women do not engage in some of the higher-risk sports (eg, football). Most athletes are involved in high school sports at the time of death (about $75 \%$ ), and less commonly in college or professional competition.

Although the majority of sudden deaths in competitive athletes have been reported in white males, a substantial proportion (more than 40\%) are African-Americans [11] (including the majority of HCM-related athletic field deaths). The substantial number of HCM sudden deaths in young black male athletes' contrasts sharply with the infrequent identification of black patients with HCM in hospital-based populations. These observations emphasize the disproportionately lesser access to subspecialty medical care between the AfricanAmerican and white communities in the United States, which makes it less likely that young black male, will receive the diagnosis of HCM. Consequently, African-American athletes with HCM are also less likely to be disqualified from competition to reduce their risk for sudden death, in accordance with the recommendations of Bethesda Conference [12,13].

In contrast with the USA, where customary practice is limited to history and physical examinations [12-17], in Italy, the introduction in the last 25 years of a systematic pre-participation screening program, which routinely includes a 12-lead ECG, has allowed identification of many athletes previously undiagnosed with HCM, as the electrocardiogram is abnormal in up to $95 \%$ of HCM patients [18-21]. In particular, Italian investigators have reported an almost $90 \%$ decline in the annual incidence of sudden cardiovascular death in competitive athletes (a result largely due to reduced mortality from cardiomyopathy) for the Veneto region of northeastern Italy. This change in the death rate occurred in parallel with progressive implementation of nationwide mass screening and the increasing identification of affected athletes who were then disqualified from competitive sports to lower their risk.

Maron et al., in a recent comparison of USA and Italian experiences, described a similar sudden death rate among young competitive athletes in recent years [15]. These data seem to not support the Italian 
evidence of a lower mortality rate associated with pre-participation screening program including

However, because of the strong impact of sudden death in sport life, independently of different pre-participation screening strategies, it should be stressed the concept that multiple sources are additive and beneficial in identifying the maximum number of sudden death events. In this regard, recently Maron et al. proposed identification of cases of sudden deaths in college athletes using internet-based, public domain methodology [22].

Moreover, the role of ECG remains crucial (Figure 1). The 12-lead ECG pattern is abnormal in $75 \%$ to $95 \%$ of HCM patients and typically demonstrates a wide variety of patterns, including elevated QRS voltages, intra-atrial or left intraventricular conduction abnormalities, pathologic Q waves (depth $>2 \mathrm{~mm}$ ) and significant re-polarization abnormalities (ST depression, negative T waves). For example, deep T-wave inversion of $>2$ contiguous anterior or lateral leads (but not a VR and III) are of major concern for sports cardiologists, because may represent the first and only sign of an inherited heart muscle disease [23]. Providing medical clearance for an asymptomatic athlete without a family history of sudden death is especially changeling in the presence of these abnormal repolarization patterns, highly suggestive of an inherited cardiomyopathy.

However these ECG pattern, some of which may be observed in well trained athletes, raise a suspicion of HCM, but have a poor diagnostic value, in absence of evidence of structural abnormalities. Transthoracic echocardiography significantly improves the diagnostic power of screening in the detection of both mild and serious cardiac conditions in the athletic populations [24].

Thus, despite different pre-participation screening strategies, when a cardiovascular abnormality is identified in a competitive athlete, several considerations arise:

(1) Level of risk for sudden death if participation in organized sports continues;

(2) Likelihood that risk would be reduced if systematic training and competition were terminated;

(3) Criteria to formulate appropriate eligibility or disqualification decisions.

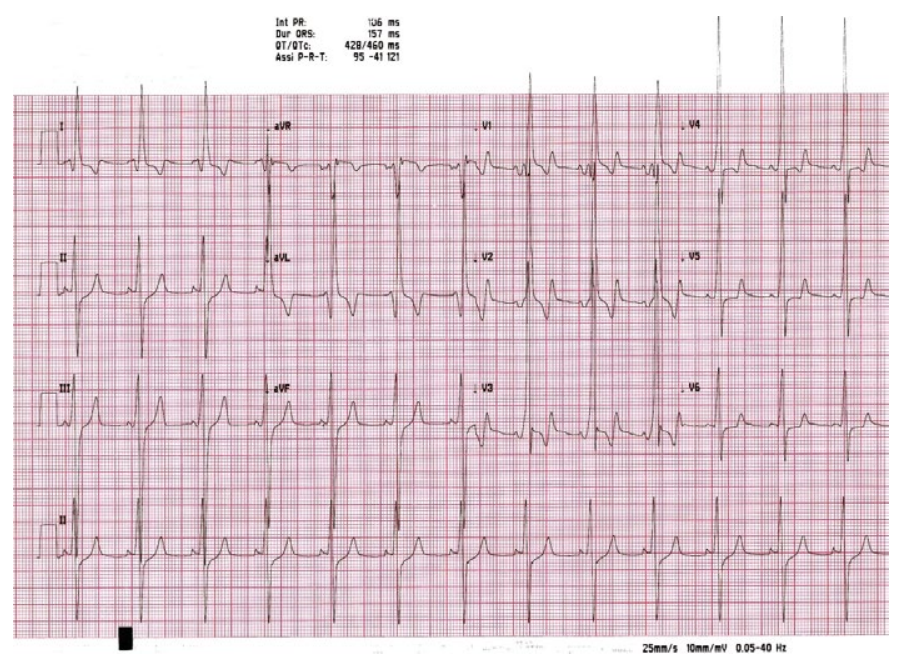

Figure 1. ECG at rest of a non agonistic athlete with a suspicion of Wolf-Parkinson-White. ECG suggests the diagnosis of HCM, later confirmed by imaging (by Chapter 19, Sport Cardiology Texbook, Springer 2012).
It should be underscored that the risk associated with intense physical exertion for sports participants with cardiovascular abnormalities is difficult to quantify with any precision, given the extreme and unpredictable physiologic circumstances to which individual athletes may be exposed. Indeed, only some HCM-related sudden deaths are associated with intense physical activity and not all trained athletes with this disease die suddenly during their competitive phase.

In this regard, the American College of Cardiology (ACC) 36th Bethesda Conference and European Society of Cardiology (ESC) offers expert consensus panel recommendations and clear benchmarks for clinical practice $[12,13]$. In line with these recommendations young athletes with the unequivocal diagnosis of HCM are discouraged from competitive athletic participation, with the exception of low-intensity sports (eg, golf and bowling).

Because of the potential and dramatic event of sudden death among young athletes, especially in case of strong intensity sports, the identification of higher risk athletes is crucial. First of all, it needs to discriminate physiological LV hypertrophy in trained athletes from pathological hypertrophy in HCM affected subjects.

Secondly, in case of HCM diagnosis, an accurate medical qualification decision-making process has to be performed. Obviously, this process may be very problematic, given the personal aspirations of the athlete versus the mandate of the physician to protect patients from circumstances which could provoke unacceptable risks. However, if individual risk stratification is difficult, on the other hand the identification of patients at low risk is easier.

In fact it's possible to define at low risk of sudden death the HCM affected patients with the following characteristics:

- absence of symptoms, in particular syncope or prolonged, recurrent and effort palpitations;

- mild hypertrophy $(<18 \mathrm{~mm})$;

- absence of atrial enlargement;

- absence of dynamic LVOT obstruction or mitral regurgitation at rest and during exercise;

- absence of effort hypotension (blood pressure reduction $>20 \mathrm{mmHg}$ during exercise;

- normal transmittal flow patter and normal TDI of the right ventricle;

- absence of significant supraventricular and ventricular arrhythmias:

- Absence of late enhancement in MRI.

These low risk patients are eligible, under periodic controls, for low intensity sports (eg, golf, sailing, riding and bowling).

\section{Conclusion}

Actually, sudden deaths in young competitive athletes are highly visible events with profound impact on the physician and lay communities.

Despite of the large controversy, the magnitude of this public health issue supports the needing of a systematic screening strategy and a mandatory reporting of athlete sudden deaths to a National registry. In Italy the existence of a law on health protection of competitive sports 
since 1982 has lead to the creation and the revision of Cardiological guidelines (called COCIS) which have reached their fourth edition (1989-2009). Because of aspiration of creating a unique and authoritative document applicable to the global sport medicine, consensus criteria and recommendations for eligibility and disqualification of athletes with HCM have proved useful to the practicing community.

\section{References}

1. Maron BJ (2002) Hypertrophic cardiomyopathy: a systematic review. JAMA 287: 1308-1320. [Crossref]

2. Gersh BJ, Maron BJ, Bonow RO, Dearani JA, Fifer MA, et al. (2011) ACCF/AHA Guidelines for the Diagnosis and Treatment of Hypertrophic Cardiomyopathy: a report of the American College of Cardiology Foundation/American Heart Association Task Force on Practice Guidelines. J Am Coll Cardiol 58: 212-260.

3. Maron BJ (2009) Distinguishing hypertrophic cardiomyopathy from athletes heart physiological remodelling: clinical significance, diagnostic strategies and implications for pre- participation screening. Br J Sports Med 43: 649-656. [Crossref]

4. Pelliccia A, Maron MS, Maron BJ (2012) Assessment of left ventricular hypertrophy in a trained athlete: differential diagnosis of physiologic athlete's heart from pathologic hypertrophy. Prog Cardiovasc Dis 54: 387-396. [Crossref]

5. Pagourelias ED, Efthimiadis GH, Koudi E, Zoron P, Giannoglu G, et al. (2013) Efficacy of various "classic" echocardiographic and laboratory indices in distinguishing the "gray zone" between athele's heart and hypertrophic cardiomyopathy: a pilot study. Echocardiography 30: 131-139. [Crossref]

6. Pagourelias ED,Giannoglu G, Koudi E, Efthimiadis GK, Zoron P, et al. (2010) Brian natriuretic peptide and the athele's heart: a pilot study. Int J Clin Pract 64: 511-517. [Crossref]

7. Fioranelli M, Frajese G (2012) Sports Cardiology, from diagnosis to clinical management. Springer, USA.

8. Luikx T, Cramer MJ, Buckens CF, Zaidi A, Rienks R,et al. (2013) Unravelling the gray zone: cardiac MRI volume to wall mass ratio to differentiate hypertrophic cardiomyopathy and the athlete's heart. Br J Sports Med. [Crossref]

9. Mangold S, Kramer U, Franzen E, Erz G, Bretscneider C, et al. (2013) Detection of cardiovascular disease in elite athletes using cardiac magnetic resonance imaging. Rofo 185: 1167-1174. [Crossref]

10. Sylvester J, Seidenburg P, Silvis M (2014) The dilemma of genotype positive-phenotype negative hypertrophic cardiomyopathy. Curr Sports Med Rep 13: 94-99. [Crossref]

11. Maron BJ (2007) Hypertrophic cardiomyopathy and other causes of sudden cardiac death in young competitive athletes, with considerations for preparticipation screening and criteria for disqualification. Cardiol Clin 25: 399-414. [Crossref]

12. Maron BJ, Zipes DP (2005) Introduction: eligibility recommendations for competitive athletes with car- diovascular abnormalities. J Am Coll Cardiol 45: 1312-1375. [Crossref]

13. Pelliccia A, Zipes DP, Maron BJ (2008) Bethesda conference \#36 and the European
Society of Cardiology Consensus Recommendations reviseted a comparison of U.S. and European criteria for eligibility and disqualification of competitive athletes wih cardiovascular abnormalities. J Am Coll Cardiol 52: 1990-1996. [Crossref]

14. Maron BJ, Thompson PD, Ackerman MJ, Balady G, Berger S, et al. (2007) Recommendations and considerations related to preparticipation screening for cardiovascular abnormalities in competitive athletes. 2007 Update: A scientific statement from the American Heart Association Council on Nutrition, Physical Activity, and Metabolism: Endorsed by the American College of Cardiology Foundation. Circulation 115: 1643-1655. [Crossref]

15. Corrado D, Basso C, Thiene G (2010) Comparison of U.S and Italian experiences with sudden cardiac deaths in young competitive athletes and implications for preparticipation screening strategies. Am J Cardiol 105: 421-422. [Crossref]

16. Maron BJ, Haas TS, Murphy CJ, Ahluwalia A, Rutten-Ramos S (2014) Incidence and causes of sudden death in U.S College athletes. $J$ Am Coll Cardiol 63: 1636-1643. [Crossref]

17. Maron BJ, Haas TS, Doerer JJ, Thompson PD, Hdges JS (2009) Comparison of U.S and Italian experiences with sudden cardiac deaths in young competitive athletes and implications for prepartecipation screening strategies. Am J Cardiol 104: 276-280. [Crossref]

18. Corrado D, Pelliccia A, Bjørnstad HH, Vanhees L, Biffi A, et al. (2005) Cardiovascular preparticipation screening of young competitive athletes for prevention of sudden death: proposal for a common European protocol Consensus Statement of the Study Group of Sport Cardiology of the Working Group of Cardiac Rehabilitation and Exercise Physiology and the Working Group of Myocardial and Pericardial Diseases of the European Society of Cardiology. Eur Heart J 26: 516-524. [Crossref]

19. Pelliccia A, Maron BJ (1995) Preparticipation cardiovascular evaluation of the competitive athlete: Perspectives from the 30-year Italian experience. Am J Cardiol 75: 827-828. [Crossref]

20. Biffi A, delise P, Zeppilli P, Giada F, Pelliccia A, et al. (2013) Italian cardiological guidelines for sports eligibility in athletes with heart disease: part 1. Italian Society of Sports Cardiology and Italian Sports Medicine Federation. J Cardiovasc Med (Hagerstown) 14: 477-499. [Crossref]

21. Biffi A, delise P, Zeppilli P, Giada F, Pelliccia A, et al. (2013) Italian cardiologica guidelines for sports eligibility in athletes with heart disease: part 2. Italian Society of Sports Cardiology and Italian Sports Medicine Federation. J Cardiovasc Med (Hagerstown) 14: 500-515. [Crossref]

22. Maron BJ, Murphy CJ, Haas TS, Ahluwalia A, Garbwrich RF (2014) Strategies for assessing the prevalence of cardiovascular sudden deaths in young competitive athletes. Int J Cardiol 173: 369-372. [Crossref]

23. Wilson MG, Sharma S, Carre' F, Charron P, Richard P, et al. (2012) Significance of deep T-wave inversions in asymptomatic athletes with normal cardiovascular examinations: pratical solutions for managing the diagnostic conundrum. Br J Sports Med 46: 51-58. [Crossref]

24. Rizzo M, Spataro A, Cecchetelli C, Quaranta F, Livrieri S, et al. (2012) Structural cardiac disease diagnosed by echocardiography in asymptomatic young male soccer player:implications for preparticipation screeining. Br J Sports Med 46: 371-373. [Crossref]

Copyright: C2015 Piro M. This is an open-access article distributed under the terms of the Creative Commons Attribution License, which permits unrestricted use, distribution, and reproduction in any medium, provided the original author and source are credited. 